\title{
NOTAS SOBRE LA PERSONALIDAD Y EL PENSAMIENTO DE D. PABLO LUCAS VERDU
}

\author{
Javier Caño Moreno \\ Director del Departamento de Derecho Constitucional y Administrativo \\ Universidad de Deusto
}

Sumario: 1. La persona. 2. Su pensamiento, ideas y contribución al Derecho Público vasco. 2.1. Concepción del Derecho. 2.2. Contribución al Derecho Autonómico vasco.

En el intento de ordenar las diferentes ideas, imágenes y sensaciones que me suscita la persona de Don Pablo - afecto, reconocimiento, respeto y admiración - he venido a parar en el concepto de institución $y$, ciertamente, me parece que es el más ajustado para expresar lo que él representa para la Universidad de Deusto.

No olvido que fue él mismo quien advirtió del peligro de abusar de esta categoría ${ }^{1}$, pero recuerdo también que A. Brown ${ }^{2}$ definió la institución como concepto «ómnibus» porque dentro de él tienen derecho a viajar todo tipo de significados: sociológicos, jurídicos, culturales, políticos y personales.

La característica externa de toda institución es la duración y permanencia en el tiempo, pero la razón de esta permanencia, y por tanto la esencia de la institución, es la vigencia y actualidad de las ideas y valores que representa y la aceptación y adhesión que sigue suscitando en el medio social.

Desde este punto de vista, Don Pablo es una institución deustense. No sólo porque dura y permanece en el tiempo - lo cual es obvio- sino porque su persona e ideas se mantienen actuales, gozan de aceptación y siguen suscitando adhesiones en este medio académico y más allá de él.

De ambas cosas pretendo hablar, aunando afecto y agradecimiento a la persona con respeto y admiración por sus ideas, por más que resulte difícil separar ambas dimensiones ya que su biografía, como ha escrito su esposa, Dña. Carmen Murillo de la Cueva, es esencialmente biografía universitaria ${ }^{3}$.

${ }^{1}$ Lucas Verdú, P., Principios de Ciencia Política.

2 Brown, A., Institución y Sociedad.

3 Murillo de la Cueva, C., Libro Homenaje a D. Pablo Lucas Verdú. 


\section{La persona}

Don. Pablo a su paso por Deusto no sólo ha dejado escuela y discípulos, sino simpatía y amigos. Profesor singular y arquetipo de vida y docencia universitarias. Su mundo y su vida ha sido y sigue siendo la Universidad: estudio, investigación, docencia y dedicación. Todo ello en estado académicamente puro, sin contaminación mercantil alguna, en auténtica dedicación exclusiva.

De mi etapa de doctorando recuerdo su preocupación no sólo por el progreso intelectual de los trabajos de tesis, sino por las circunstancias personales, familiares y profesionales de los doctorandos, estableciéndose una relación personal que acompañada de un magisterio discreto, cercano y respetuoso, constituyen una experiencia inolvidable y convierten a cada discípulo en amigo.

Cualquier comentario le sirve de pretexto para suministrar generosamente información, datos y bibliografía sobre autores clásicos y modernos. En realidad, él mismo es un clásico y, por tanto, actual, ya que los clásicos no lo son por antigüedad, sino por modernidad y actualidad. Es, en fin, una sorpresa continua y amena. Es D. Pablo, para todos nosotros singular e irrepetible.

Nacido en Salamanca, en 1923, presenta una trayectoria académica de más de cincuenta años:

—En 1948 defiende su primera tesis doctoral en la Universidad de Madrid.

—En 1950 lee su segunda tesis en Bolonia, incorporándose ese mismo año como profesor adjunto a la Universidad de Salamanca. Esta etapa salmantina, que dura hasta 1958 le permitió contactar con Tierno Galván y R. Morodo y crear el «Boletín Informativo del Seminario de Derecho Político», desde el que comenzaron a ejercer un notable influjo sobre los estudiantes de la época con sus aportaciones y comentarios críticos al sistema político vigente ${ }^{4}$.

—En enero de 1958 toma posesión de la cátedra de Derecho Político de Santiago de Compostela, etapa que dura seis años.

—En 1964 comienza su relación con la Universidad de Deusto que dura hasta el día de hoy. Primero como catedrático y luego como Presidente del Tribunal de Licenciatura de la Facultad de Derecho. Aunque más tarde pasó a Valladolid (1977) y luego a

\footnotetext{
${ }^{4}$ Murillo de la Cueva, C., op. cit.
} 
Madrid (1978), sus lazos con Bilbao y el País Vasco, desde Deba a Algorta, no se han interrumpido nunca.

Este cordón umbilical con el País Vasco, reforzado y prolongado en descendencia vasca, le permitió escribir un magnífico artículo — «Entender y sentir al Pueblo Vasco»— merecedor del Primer Premio de Periodismo del «Correo Español y el Pueblo Vasco» en el que refleja esa actitud de comprensión y apertura tan característica de su persona.

Fue el P. Alvarez, S.J., quien se acercó a Santiago de Compostela para ofrecerle la cátedra de Derecho Político en la Universidad de Deusto, y no parece que se demorase mucho la decisión a pesar, como comenta su esposa ${ }^{5}$, de las dificultades de trasladar a una familia, ya por entonces numerosa. Lo cierto es que esta decisión supuso un doble beneficio. Para Deusto, porque se benefició de su docencia y prestigio y para D. Pablo, porque tuvo la oportunidad de entrar en contacto directo con una realidad políticamente rica y potencialmente atractiva para un investigador de Ciencia Política.

Tuve la fortuna de conocer a D. Pablo en esta época, y mis recuerdos hasta el día de hoy abarcan al Profesor, al compañero de Claustro, al colaborador en Congresos y Jornadas de aquella primera Administración Vasca, al Director de Tesis y al Presidente del Tribunal de Licenciatura.

- Como profesor le conocí en 1967. Catedrático con texto propio -Principios de Ciencia Política-cuyo Tomo I publicó precisamente ese año. El nombre de la asignatura era Derecho Político, ya que por aquel entonces ni teníamos ni estábamos en Constitución. Según sus palabras, esta obra la comenzó en Santiago de Compostela y la terminó en Bilbao donde encontró tranquilidad académica, consideración y nuevos alumnos que en nada se diferenciaban en talante, curiosidad científica y preocupaciones políticas de los agudísimos estudiantes gallegos ${ }^{6}$.

Como alumno de aquella época, puedo confirmar que las clases de D. Pablo, sus comentarios y críticas al sistema vigente, constituían reclamo natural para la asistencia masiva. Clases eruditas y amenas que sembraron más de un compromiso y vocación políticas y a muchos nos abrieron horizontes y nostalgia constitucional

5 Murillo de la Cueva, C., op. cit.

${ }^{6}$ LuCAS Verdú, P., La lucha contra el positivismo jurídico en la República de Weimar. 
por un Estado de Derecho parangonable al que gozaban otros países europeos.

Singular en la manera de hablar y de decir. Catedrático de una pieza, en el fondo y en la forma. Desde el vestir enlutado por aquel entonces, al caminar combinado de impulsos frontales y oscilaciones laterales a derecha e izquierda.

Si es cierto, como antes he dicho, que ni teníamos ni estábamos en Constitución, sus clases hicieron posible que al menos nos sintiéramos en Constitución durante unas horas.

-En 1971, al incorporarme como Profesor a la Universidad de Deusto, coincidí con D. Pablo en el Claustro de la Facultad de Derecho. Recuerdo algunas de sus intervenciones, esperadas y respetadas por quienes éramos entonces profesores in fieri especial mente la que tuvo lugar en el caso Añoveros que fue una lección de finura académica y esgrima ideológica entre los pesos pesados del Claustro en torno a la figura canónica del odium plebis, justificación aducida por Arias Navarro para remover de la sede episcopal al Obispo de Bilbao.

En torno al Seminario de Derecho Político reunió a un selecto grupo de jóvenes, hoy destacados Profesores, con quienes gustaba pasear por los tránsitos en rigurosa y peripatética formación eclesiástica: hacia delante y hacia atrás. Hacía Universidad en las aulas, en el Seminario y en los pasillos.

—En los años 80, incorporado yo al Gobierno Vasco y D. Pablo en Madrid, siguió siempre dispuesto a colaborar cuantas veces se le solicitó, en Congresos y Jornadas, aportando sus conocimientos a la consolidación del Estado Autonómico y a la solución de los problemas políticos del País Vasco. Recuerdo entre otras:

- Primeras Jornadas de Estudio sobre el Estatuto de Autonomía, en 1981.

- Primer Congreso de Derecho Civil Vasco, en 1982.

- Jornadas de Estudio sobre la actualización de los derechos históricos, en 1985.

- II Congreso Mundial Vasco, en 1987.

-En 1992, finalizada mi etapa política, decidí enfrentarme al compromiso de la tesis doctoral, circunstancia que me permitió conocer nuevas dimensiones de la personalidad humana e intelectual de D. Pablo.

Llegué una tarde de verano a su casa de Algorta con proyectos claros pero sin coberturas doctrinales ni bibliográficas. Expuse mi idea en pocos minutos e inmediatamente me sorprendió con 
un torrente de sugerencias y bibliografía. Aquel encuentro fue un regalo. Fui de simple consulta y salí con ideas, planes, lecturas y Director. Este encuentro providencial cuajó en una sintonía intelectual y afectiva que he tenido oportunidad de profundizar posteriormente como Decano de la Facultad de Derecho y miembro del Tribunal de Licenciatura que él preside.

Esta relación desordenada de impresiones personales y subjetivas quedaría incompleta, puesto que su biografía es básicamente universitaria, sin una mención final a las distinciones con que ha sido galardonado y a su producción intelectual ${ }^{7}$.

D. Pablo ha sido galardonado con las siguientes distinciones:

-Encomienda con placa de Alfonso X el Sabio.

- Académico de Número de la Real Academia de Ciencias Morales y Políticas.

-Doctor Honoris Causa por seis Universidades.

En cuanto a su producción intelectual - libros, ensayos, artículos, etc...- hasta el año 2002 alcanzaba la cifra de 232,distribuidos así:

-Sobre pensamiento político y social. . . . . . . . . . 24

—Sobre Ciencia Política .................. 44

—Sobre Derecho Constitucional . . . . . . . . . . . 150

—Sobre Derecho Internacional y Europeo. . . . . . . . 8

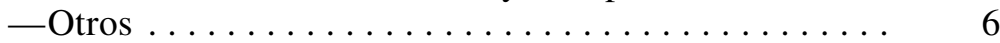

\section{Su pensamiento, ideas y contribución al Derecho Público vasco}

A D. Pablo le gusta repetir, parafraseando a Fichte, que el tipo de doctrina y de filosofía que se tiene depende del hombre que se sea ${ }^{8}$.

Según su esposa ${ }^{9}$, la cosmovisión de D. Pablo parte de la dignidad humana y de la influencia de la Teología Cristiana en la Teoría del Estado. Se inspira en el iusnaturalismo crítico, personalista, comunitario y valorativo, lo que le induce a destacar la dimensión axiológica de las Constituciones.

Este plus valorativo, superador del normativismo y del sociologismo, le aproxima al institucionismo, más en la línea de Hauriou que

\footnotetext{
7 Datos recogidos de Murillo de la Cueva, C., op. cit.

${ }^{8}$ LuCAS Verdú, P., La lucha contra el positivismo jurídico en la República de Weimar.

9 Murillo de la Cueva, C., op. cit.
} 
de Romano, y a posiciones cercanas a las defendidas por R. Smend, H. Heller y Mortati.

En su monografía La lucha contra el Positivismo Jurídico en la República de Weimar $^{10}$, el propio D. Pablo define así su pensamiento:

— «Mis convicciones profundas y últimas y, por supuesto, la educación y formación recibidas, me alejaron, en principio y hasta hoy, de cualquier clase de positivismo jurídico: voluntarista, formalista y sociológico».

— «Mi larga estancia en Italia, donde trabajé con los Profesores Battaglia y Pergolesi contribuyó a dos cosas: a ensanchar mis conocimientos filosófico-jurídicos, puesto que con Battaglia me adentré en el ámbito del espiritualismo cristiano, y con Pergolesi seguí la dirección del método técnico-jurídico. Ayudado por ellos tomé contacto con las principales obras y autores del período weimeriano: Smend, Schmitt, Heller y otros».

— «De Smend me atrajo su reacción contra las evaporaciones de normativismo de Kelsen. Por otra parte, era conveniente alejarse de las tentaciones hiperrealistas para no incurrir en un exagerado reduccionismo socio-económico y centrar la problemática constitucional: ni una especulación hiperformalizada, ni una relativización sociologizante. La lectura de Mortati y Kagi me ayudaron a adoptar tal posición ponderada».

Aprecia en Smend el afán de «integrar» el Estado aunque a veces pierde de vista la capacidad normativizadora del Derecho y de la Constitución destacadas por Kelsen, a quien, por el contrario, se le escapa la realidad subyacente. Por ello, ve en Heller el equilibrio, el intento de mediar entre normatividad y normalidad para conseguir la normalización.

Finalmente, reconoce la influencia del institucionismo de Hauriou, cuyas tesis armonizadas con las de Smend, le permitieron ensayar una conceptualización del Estado Autonómico como «pluralidad institucional integrada ${ }^{11}$.

\subsection{Concepción del Derecho}

De acuerdo con las premisas expuestas y con sus propias manifestaciones su concepción del Derecho parte de la necesidad de superar el

\footnotetext{
10 LuCAS Verdú, P., op. cit.

11 LuCAS Verdú, P., op. cit.
} 
positivismo y el normativismo jurídicos ${ }^{12}$ de raíz Kelseniana, a quienes imputa haber incurrido en solipsismo jurídico:

— «Para el normativismo, en el Ordenamiento Jurídico no existe nada más allá — derecho natural, valores—, ni más acá —costumbres, instituciones $n i$ por debajo - realidades sociales. Las magnitudes trascendentes no interesan. Lo que importa es el Derecho Positivo, el establecido por el Estado: la Ley».

— «El positivismo jurídico es la ideología, la teoría y la técnica al servicio de un sistema establecido. Es prepotente y conservador. Ha olvidado las raíces iusnaturalistas que lo alentaron contra los abusos del Antiguo Régimen, su carácter revolucionario original, y recluta a sus servidores entre burócratas identificados con el "establishment", entre profesores temerosos del cambio y entre abogados ávidos de notoriedad y prebendas».

Estas duras críticas ideológicas a los fundamentos del normativismo no pretenden anular el positivismo jurídico, ni el tratamiento técnico-jurídico del Derecho, sino como diría Germann, integrarlo en un sistema valorativo.

En conclusión, su concepción del Derecho y especialmente del Derecho Constitucional, contiene tres ingredientes básicos, a tener en cuenta:

—raíz sociológica e historicidad;

- ley, costumbre e instituciones;

— valores, fines, estimativa y fundamentos axiológicos.

De ahí su lucha por liberar al Derecho Constitucional del peligro de Administrativización ${ }^{13}$, superar una exclusiva concepción racional normativa de la Constitución, puramente formal. Esta visión, que separa el ser y el deber ser, es más propia de las normas administrativas que de las políticas y supone volver a Kelsen, olvidando la lucha de Smend, Schmitt y Heller.

El Derecho Constitucional hunde sus raíces en la realidad social y en la historia, es la normación e institucionalización de estructuras y realidades políticas preexistentes. Este enlace con la realidad histórico-social, debe complementarse con los aspectos técnico-jurídicos, normativos e institucionales de la Constitución y con su dimensión axiológica y estimativa, representada básicamente en los valores superiores.

12 LuCAS Verdú, P., op. cit.

13 Lucas Verdú, P., «Como Derecho Administrativo». Rev. Derecho Público, 1982. 


\subsection{Contribución al Derecho Autonómico vasco}

No está de más recordar en estos tiempos de crisis constitucional y estatutaria por los que atraviesa la presente coyuntura política, al menos en el País Vasco, que las potencialidades de autogobierno del Estatuto, dependen directamente del desarrollo e interpretación de la Constitución.

No es lo mimo una concepción normativista, técnico-jurídica, estricta, legalista y formal, propia del Derecho Administrativo, que otra flexible, abierta, integradora propia de un Constitucionalismo útil.

Desde mi punto de vista, a partir de 1981, el testigo del desarrollo autonómico ha sido entregado a un equipo de juristas expertos, que sumando sus argumentos administrativistas a una voluntad política desfalleciente han logrado transformar la Constitución y el Estatuto, de lugar de encuentro e integración políticas, en normas frías y desnudas.

Han perdido por el camino la sustancia política, de forma que el envaramiento normativista que les rodea, resulta difícilmente conciliable con aquella vocación aperturista y plural que permitía soluciones y arreglos jurídico-políticos diversos.

Lo característico del Derecho Político no es patrocinar interpretaciones únicas, sino señalar alternativas jurídicas distintas para aplicar en cada caso la más conveniente para la solución de los problemas, la integración y el consenso. Herrero de Miñón ${ }^{14}$ dice que hay dos formas de entender el Derecho Político: como ratio scripta a la que ha de plegarse la realidad, o como flexible aproximación a la vida para encauzarla de la manera más pacífica posible. La primera es una mecánica, la segunda es un arte.

D. Pablo al defender su concepción de Derecho Constitucional como Derecho Político y no como Derecho Administrativo, se adscribe a la concepción del Derecho como arte, no como mecánica. Al buscar la integración política, sin desdeñar el método técnico-jurídico, equilibrando realidad social, norma, instituciones y valores, salva no sólo la validez, sino la eficacia constitucional.

Esta es, por tanto su principal aportación.

En un ámbito más concreto sus contribuciones más directas se han concentrado, especialmente, en el ámbito de los derechos históricos — «penetración de la historicidad en la Constitución española»-, en la concepción institucional de estos derechos —como «constitución sustancial»—, en la «Teoría preposicional de la Constitución»—que yo

14 Herrero de Miñón, M., Ideas sobre el Problema Vasco, 2003. 
me he permitido aplicar al Estatuto y a los derechos históricos- y en la compatibilidad Fueros y Constitución.

Precisamente, con motivo de esta última cuestión, frente a quienes tildan de conservadurismo la alegación a los derechos históricos incompatible con un constitucionalismo racional y moderno, escribe unas páginas clarificadoras y de máxima actualidad, con las que pongo punto final a este trabajo ${ }^{15}$ :

— «La burguesía insatisfecha se sirvió en un primer momento, para derribar las estructuras anquilosadas del Antiguo Régimen, del iusnaturalismo revolucionario. Pero, cuando se acomoda en el nuevo sistema, se desprende de los ideales y lo transforma en positivismo legalista y garantista que la salvaguarda frente a grupos y regiones que esgrimen derechos e historia anteriores a la Constitución».

— «El concepto racional-normativo de Constitución, fruto de la imaginación jurídico-política de la burguesía, utiliza la dogmática jurídica para garantizar el monopolio legislativo del parlamento y el rechazo de factores jurídicos irreductibles a una formulación normativa».

— «El concepto racional-normativo formaliza el poder constituyente de la nación en poder del Parlamento, representación de los grupos de intereses, hoy monopolizado por los Partidos políticos. Así se evita que los nuevos movimientos revolucionarios amenacen al sistema invocando argumentos análogos a los del iusnaturalismo revolucionario fundador del constitucionalismo. Así, este iusnaturalismo se desustancializa y se convierte en mera técnica garantista».

— «De este modo tienden a petrificarse, a deshistorificarse, pregonando la rigidez constitucional del poder constituyente que ya no radica en la nación, sino en los partidos. En ello late una clamorosa contradicción: nacidos de la protesta de una clase ascendente, ahora se oponen al cambio que piden nuevos estratos sociales, grupos o regiones que no han renunciado a su legado histórico. Resulta que invocaron argumentos democráticos en una coyuntura histórica, y ahora impiden que se esgriman razones democráticas de los marginados que reclaman su propia historia».

15 Lucas Verdú, P., Penetración de la historicidad en el Derecho Constitucional español. 
— «Para conseguir este logro — permanencia y garantismo- recurren a la dogmática jurídica positivista. Se utilizaron valores y principios para conseguir el Poder, y una vez instalados en él, se renuncia a los valores y a la historia para refugiarse en la Ley».

Con la transcripción de estos fragmentos pongo fin a estas líneas, en la confianza de haber trasmitido y justificado la dimensión institucional, moderna y actual, de la persona y el pensamiento de D. Pablo Lucas Verdú. 